\title{
Hepatitis B Virus Infection and Its Determinants among Pregnant Women in Ethiopia: A Systematic Review and Meta-Analysis
}

\author{
Addisu Alehegn Alemu (D), Liknaw Bewket Zeleke $\mathbb{D}^{D}$, Bewket Yesarah Aynalem $(\mathbb{D}$, \\ and Getachew Mullu Kassa
}

College of Health Sciences, Debre Markos University, Debre Markos, Ethiopia

Correspondence should be addressed to Addisu Alehegn Alemu; addisua4@gmail.com

Received 11 April 2020; Accepted 23 May 2020; Published 11 June 2020

Academic Editor: Lu-Yu Hwang

Copyright (C) 2020 Addisu Alehegn Alemu et al. This is an open access article distributed under the Creative Commons Attribution License, which permits unrestricted use, distribution, and reproduction in any medium, provided the original work is properly cited.

\begin{abstract}
Background. Hepatitis B virus (HBV) is an infectious and a global public health problem. The prevalence of HBV infection among pregnant women is between $2.3 \%$ and $7.9 \%$. HBV infection during pregnancy is associated with prenatal transmission to the fetus. HBV has an effective vaccine which reduces up to $96 \%$ of the transmission. Although different studies were conducted in Ethiopia, none of them showed the national prevalence of HBV infection among pregnant women. Therefore, this study was conducted to determine the pooled prevalence of HBV and its associated factors in Ethiopia. Methods. We followed the Preferred Reporting Items for Systematic Reviews and Meta-Analyses (PRISMA) guidelines for articles. All observational published studies were retrieved using relevant search terms in Google Scholar, African Online Journal, CINAHL, and PubMed databases. NewcastleOttawa assessment checklist for observational studies was used for critical appraisal of the included articles. The meta-analysis was done with STATA version 14 software. The $I^{2}$ statistics were used to test heterogeneity whereas Begg's and Egger's tests were used to assess publication bias. Odds ratio (OR) with a 95\% confidence interval (CI) was presented using the forest plot. Results. A total of twenty-three studies were included in this systematic review and meta-analysis. The pooled prevalence of HBV in Ethiopia was 4.75\% (95\% CI: 4.06, 5.44). The subgroup analysis showed a higher prevalence of HBV infection among pregnant women in Gambella (7.9\%) and the lowest in Southern Nations, Nationalities, and Peoples' Region (SNNPR) (2.3\%). Associated factors with HBV infection include history of multiple sexual partner $(\mathrm{OR}=6.02(95 \% \mathrm{CI}=3.86,9.36))$, blood transfusion history $(\mathrm{OR}=5.71(95 \% \mathrm{CI}=3.25,10.04))$, abortion history $(\mathrm{OR}=3.58(95 \% \mathrm{CI}=2.10,6.09))$, and history of body tattoo $(\mathrm{OR}=2.83(95 \% \mathrm{CI}=1.55,5.17))$. Conclusions. HBV infection among pregnant women is a common public health problem in Ethiopia. Multiple sexual partners, abortion history, blood transfusion history, and body tattoo were significantly associated with HBV infection. Policies and strategies should focus on factors identified in this study to improve the prevention of HBV among pregnant women.
\end{abstract}

\section{Background}

Hepatitis B virus (HBV) infection (acute and chronic) is one of the most common causes of human liver disease, and most people usually remain unaware of their infection status and present when the disease is advanced $[1,2]$. HBV is an important global public health problem [2,3], in which 350 million people had been diagnosed for chronic HBV infection and 686,000 people die each year from its complications, which include cirrhosis and hepatocellular carcinoma [2]. It is among the tenth killer disease worldwide [4-6] and named as "silent killer" [7]. It is mainly affecting developing countries [4, 8-11]. Globally, HBV infection endemicity is classified as high $(\geq 8 \%)$, intermediate $(2-7 \%)$, and low $(<2 \%)$ depending on its prevalence [12]. The HBV classification in Ethiopia is intermediate [13] and ranges between 2.3\% [14] and $14 \%[12]$.

People are usually infected with HBV through direct contact with infected blood and other body secretions. However, it can be transmitted from infected mothers to 

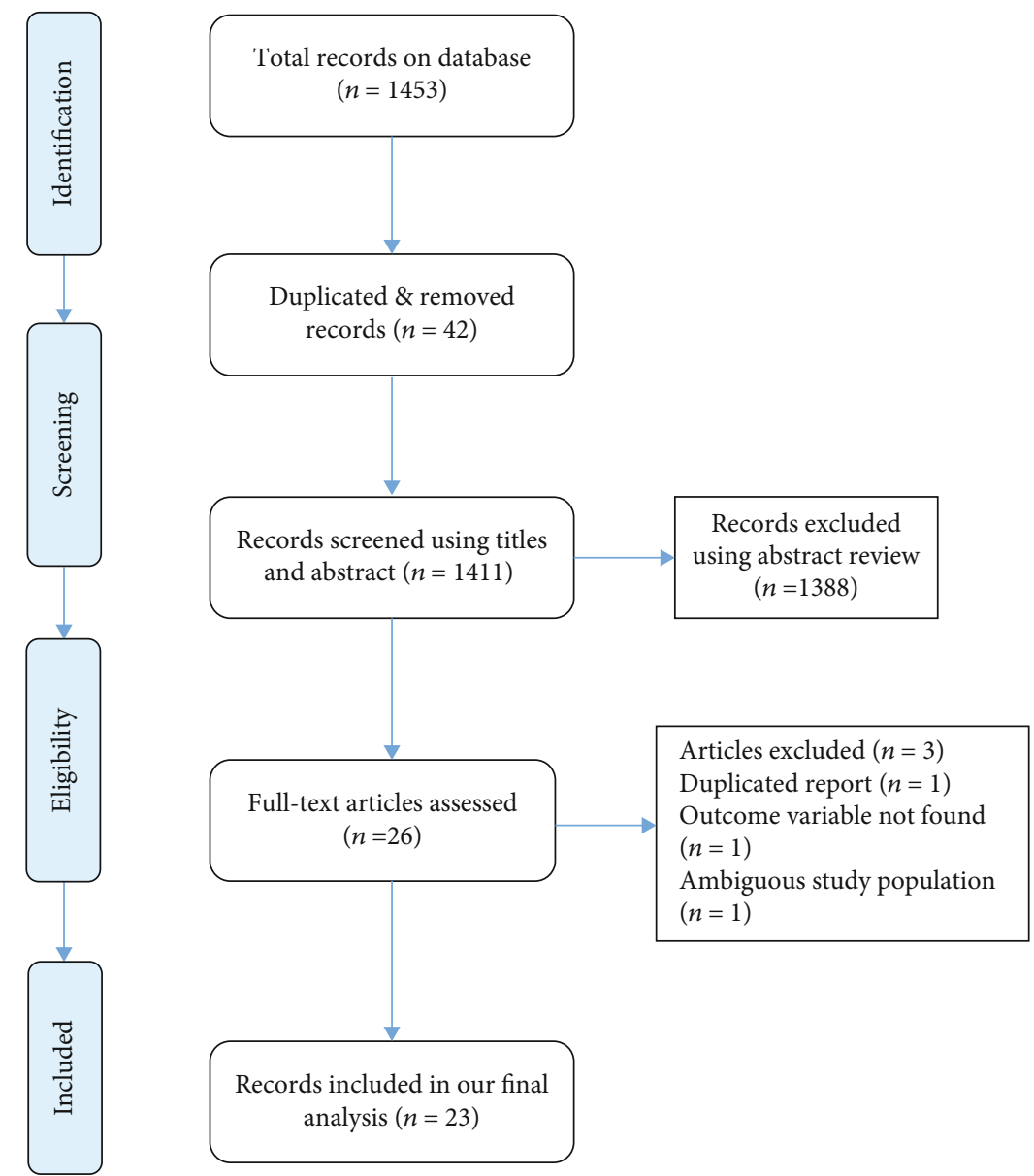

FIGURE 1: PRISMA diagram identifying studies utilized for systematic and meta-analysis of HBV infection among pregnant women in Ethiopia.

their newborns during pregnancy and delivery [15-17]. The latter is the commonest cause of the HBV infection $[5,18]$ associated with insufficient knowledge about HBV among pregnant women and the absence of universal screening of all women attending antenatal care [5, 19, 20]. Many women infected with $\mathrm{HBV}$ during their pregnancy are at increased risk of transmitting hepatitis B infection to their unborn babies $[6,11,21]$, with a $70-90 \%$ chance of perinatal acquisition and over $85-90 \%$ chance of becoming chronic carriers of the disease, the main reservoir for continued transmission of HBV $[6,22]$. In addition to the current practice, universal child vaccination and routine and continuous antenatal screening program reduce its endemicity $[11,13,23]$.

There are many studies conducted on the prevalence of $\mathrm{HBV}$ and its associated factors in Ethiopia. However, these studies presented inconsistent and inconclusive findings in the prevalence of HBV infection and its associated factors among pregnant women. Therefore, this systematic review and meta-analysis was conducted to assess the prevalence and associated factors of HBV infection in Ethiopia using available published evidence. The findings of this study will provide input in the design of proper strategies to reduce HBV infection among pregnant women.

\section{Methods}

2.1. Study Selection. We conducted this systematic and metaanalysis of all observational published studies to assess the pooled prevalence and determinants of HBV infection among pregnant women in Ethiopia. Retrieving of the included studies was done using different databases such as Google Scholar, African Online Journal, CINAHL, and PubMed without restricting study period. We carried out the selection of previous studies to include in the current study following the Preferred Reporting Items for Systematic Reviews and Meta-Analysis (PRISMA) guideline [24].

2.2. Inclusion Criteria of the Studies. Study design. All observational published studies in the English language and reported prevalence/magnitude and associated factors of HBV infection among pregnant women in Ethiopia were included.

Study period. All studies conducted from January 2004 to May 2018 and published from 2005 to January 1, 2020, were included in this review.

Participants. Women who had become pregnant at least once before or during each study.

Exposure. The magnitude/prevalence and determinants of HBV infection. Determinants are general characteristics 
TABLE 1: Descriptions of the studies included in the current study.

\begin{tabular}{|c|c|c|c|c|c|}
\hline Study ID & Study year & Prevalence & Sample & Region & Quality \\
\hline Zenebe Y, 2014 [36] & 2014 & 3.8 & 318 & Amhara & 9 \\
\hline Desalegn Z, 2016 [41] & 2014 & 6 & 215 & Addis Ababa & 8 \\
\hline Gedefaw G, 2019 [32] & 2018 & 4.7 & 338 & Amhara & 8 \\
\hline Chernet A, 2017 [47] & 2015 & 3.5 & 289 & SNNPR & 9 \\
\hline Tiruye G, 2018 [43] & 2017 & 6.3 & 320 & Harar & 7 \\
\hline Tanga A, 2019 [45] & 2017 & 7.9 & 253 & Gambella & 9 \\
\hline Tegegne D, 2014 [34] & 2012 & 3 & 265 & Addis Ababa & 6 \\
\hline Ramos JM, 2011 [39] & 2011 & 6.1 & 165 & SNNPR & 9 \\
\hline Molla S, 2015 [30] & 2013-2014 & 4.4 & 384 & Amhara & 9 \\
\hline Umare A, 2016 [44] & 2015 & 6.9 & 318 & Oromia & 9 \\
\hline Dabsu R, 2018 [33] & 2018 & 2.4 & 421 & Oromia & 7 \\
\hline Temesgen A, 2020 [11] & 2017 & 4.5 & 222 & SNNPR & 8 \\
\hline Amsalu A, 2018 [29] & $2015-2016$ & 7.2 & 475 & SNNPR & 6 \\
\hline Awole M, 2005 [37] & $2002-2003$ & 3.7 & 493 & Oromia & 7 \\
\hline Walle F, 2008 [24] & 2004 & 5.3 & 209 & Amhara & 7 \\
\hline Desalegn Z, 2016 [40] & 2014 & 5.4 & 202 & Oromia & 9 \\
\hline Yohanes T, 2016 [31] & 2015 & 4.3 & 232 & SNNPR & 8 \\
\hline Fissehatsion K, 2017 [42] & 2014 & 5 & 403 & Addis Ababa & 6 \\
\hline Metaferia Y, 2016 [35] & 2015 & 7.8 & 269 & SNNPR & 8 \\
\hline Seid M, 2014 [23] & 2014 & 4.9 & 385 & Amhara & 7 \\
\hline Mezgebo T, 2017 [46] & 2015 & 5.5 & 328 & Tigray & 6 \\
\hline Schönfeld A, 2017 [38] & 2014-2015 & 5.3 & 580 & Oromia & 7 \\
\hline Deme C, 2016 [14] & 2016 & 2.3 & 574 & SNNPR & 7 \\
\hline
\end{tabular}

that might increase or decrease the chance of women infected with HBV. It includes history of abortion, blood transfusion, multiple sexual partners, and body tattoo.

Outcome. Mothers infected with HBV.

2.3. Search Strategy. Prevalence; seroprevalence; seroepidemiology; magnitude; hepatitis B Virus; Viral hepatitis; $\mathrm{HBV}$; Hepatitis B surface antigen; HBsAg; Viral liver disease; pregnant woman and Ethiopia were MeSH terms used for searching using "OR" and "AND” Boolean operators. Additionally, we have checked the identified studies' references on the databases to find the potentially eligible studies but missed during the initial searching.

2.4. Data Extraction. Data for this study were extracted from the previous studies using an extraction form developed on the Excel sheet by the authors. Two of the authors (AAA and LBZ) participated in extracting data from the included studies. For all included studies, we have considered and recorded the publication year, author name, study design, sample size, and exposure characteristics, i.e., prevalence, history of abortion, blood transfusion, multiple sexual partners, and body tattoo. Data extraction was done using a structured form on Microsoft Excel.

2.5. Risk of Bias (Quality Assessment). An intensive assessment of all the articles included in this study was done by the two authors (AAA and LBZ). Newcastle-Ottawa assess- ment checklist [25] for observational studies was applied for assessing the quality of each study considered in this research. The tool has three sections; the first section (methodological assessment) and the second section (comparability evaluation) are rated up to five and three stars, respectively, whereas the third section was used for assessing statistical analysis and outcome for each included study. All the included articles assessed through the tool and studies that scored $\geq 6$ were taken with high quality. There was a joint discussion between the reviewers for uncertainty.

2.6. Data Synthesis and Statistical Analysis. The data entry was done through Microsoft Excel and exported to STATA version 14 software for analysis. Figures and tables were used to show the summarized and descriptive results. We have also conducted a meta-analysis to assess the pooled prevalence and determinants of the outcome variable (HBV infection). We have estimated adjusted odds ratios with their confidence intervals to measure the association. The random-effect model was considered to determine the pooled prevalence and determinants of $\mathrm{HBV}$ infection among pregnant women in Ethiopia due to the heterogeneity by study design and study regions/areas. $I^{2}$ statistics of 25,50 , and $75 \%$ were used to declare low, moderate, and high heterogeneity, respectively [26]. We had subgroup analysis by region because of the heterogeneity among the included studies to estimate the pooled prevalence. We have also checked publication bias using Egger's and Begg's tests, 


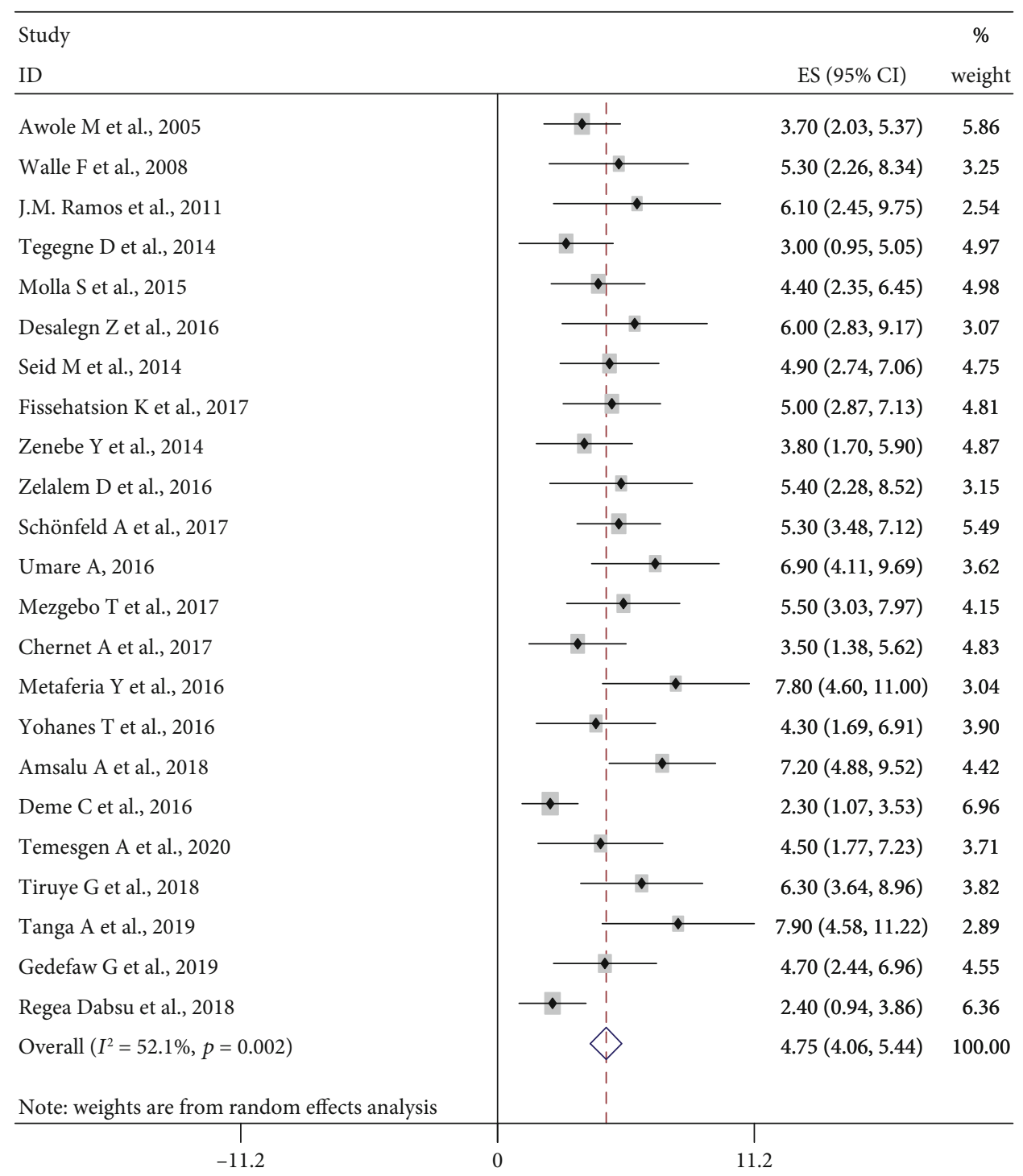

FIGURE 2: The pooled prevalence of HBV infection among pregnant women in Ethiopia.

and a $p$ value of less than 0.05 was used to declare its statistical significance $[27,28]$.

\section{Results}

3.1. Study Selection. All published observational studies on $\mathrm{HBV}$ infection among pregnant women in Ethiopia were included in this systematic and meta-analysis study. A total of 1453 articles were found on the databases, 42 of which were duplicated and removed through title screening. After screening of all the retrieved records, 1388 articles were excluded. A total of 26 full-text studies were assessed for eligibility; finally, 23 studies were included in the meta-analysis of this study (Figure 1).

3.2. Characteristics of Included Studies. Twenty-three of the studies included in the final analysis were cross-sectional $[11,14,23,24,29-47]$. The studies used health facilitybased HBV infection data among pregnant women which were collected from 2002 to 2018 in the respective health institutions. Seven articles were conducted at the Southern Nations, Nationalities, and Peoples' Region (SNNPR) [11, 14, 29, 31, 35, 39, 47], five in Amhara region [23, 24, 30, 32, $36]$, five in Oromia region [33, 37, 38, 41, 44], and three in Addis Ababa [34, 41, 42], whereas one in Tigray [46], Harar [43], and Gambella [45]. The sample size of included studies ranges from a minimum of 165 pregnant women in SNNPR [39] to 580 in Oromia [38]. Overall, a total of 7,860 pregnant women were included in this review. The quality score of the included articles ranges from 6 to 9 (Table 1).

3.3. Prevalence of $H B V$ among Pregnant Women in Ethiopia. The prevalence of HBV infection among the included studies ranges from a minimum of $2.3 \%$ (95\% CI: $1.07,3.53)$ in southern Ethiopia [14] to a maximum of $7.9 \%$ (95\% CI: $4.58,11.22)$ in Gambella Hospital, Southwestern, Ethiopia [45]. The pooled prevalence of HBV infection among pregnant women in Ethiopia was $4.75 \%$ (95\% CI: 4.06, 5.44) 


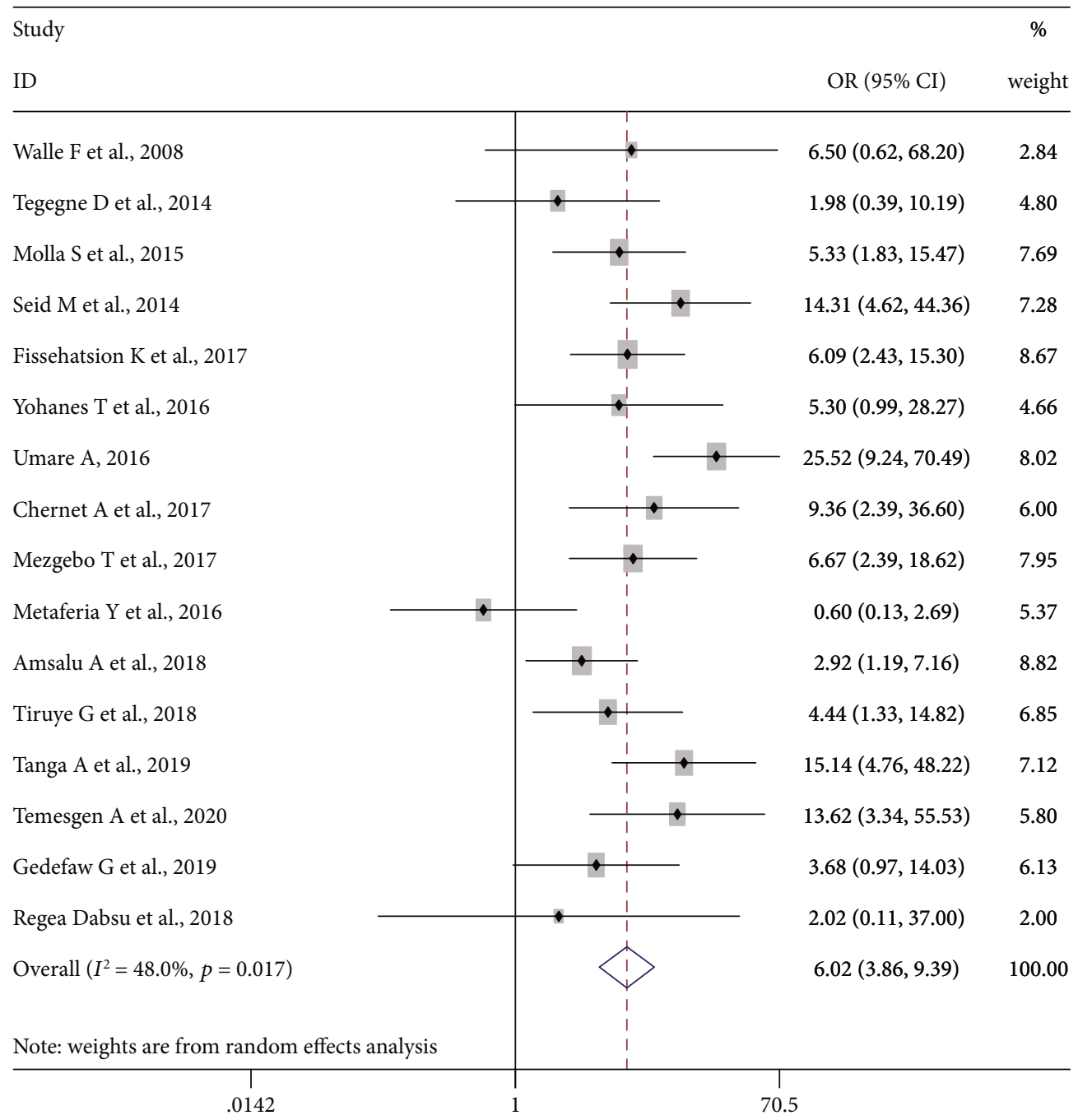

FIgURE 3: Forest plot on the effect of having multiple sexual partners on HBV infection.

based on the random-effect model analysis. Heterogeneity test showed presence of medium heterogeneity, $I^{2}=52.1 \%$ and $p$ value $=0.002$. There was also significant publication bias detected, $p$ value $\leq 0.001$ (Figure 2).

3.4. Subgroup Analysis. Subgroup analysis was conducted by different study characteristics. The subgroup analysis by region showed the highest prevalence of $\mathrm{HBV}$ infection in Gambella regional state, $7.9 \%$ (95\% CI: 4.58, 11.22), and the lowest in SNNPR, 2.3\% (95\% CI: 1.07, 3.53), even if one article was included from each region. The pooled prevalence of $\mathrm{HBV}$ infection in Amhara, Oromia, Addis Ababa, Tigray, Harar, and Gambella regions was $4.53 \%$ (95\% CI: 3.52, 5.54), 4.47\% (95\% CI: 2.92, 6.02), $4.42 \%$ (95\% CI: $2.73,6.12), 5.50 \%$ (95\% CI: 3.03, 7.97), $6.30 \%$ (95\% CI: 3.64, 8.96), and 7.90 (4.58, 11.22), respectively. The prevalence of HBV infection among pregnant women before the year 2015 was 4.70 (95\% CI: 4.12, 5.29), and it increased to $4.78 \%(95 \%$ CI: $3.09,6.47)$ after 2015 . For publication bias confirmed by the Egger test, the Duval and filled analyses were conducted to fill with unpublished studies (Table 2).
TABLE 2: Subgroup analysis of HBV infection among pregnant women by study year and region.

\begin{tabular}{lcccc}
\hline Study year & $\begin{array}{c}\text { Number } \\
\text { of studies }\end{array}$ & Prevalence $(95 \% \mathrm{CI})$ & $p$ value & $I^{2}(\%)$ \\
\hline In 2015 \& before & 16 & $4.70(4.12,5.29)$ & 0.481 & 0.0 \\
After 2015 & 7 & $4.78(3.09,6.47)$ & $\leq 0.001$ & 78.2 \\
& \multicolumn{5}{c}{ Region } & & \\
SNNPP & 7 & $4.87(3.17,6.57)$ & $\leq 0.001$ & 72.4 \\
Oromia & 5 & $4.47(2.92,6.02)$ & 0.021 & 65.5 \\
Amhara & 5 & $4.53(3.52,5.54)$ & 0.930 & 0.0 \\
Addis Ababa & 3 & $4.42(2.73,6.12)$ & 0.217 & 34.5 \\
Tigray & 1 & $5.50(3.03,7.97)$ & & \\
Gambella & 1 & $7.90(4.58,11.22)$ & & \\
Harar & 1 & $6.30(3.64,8.96)$ & & \\
\hline
\end{tabular}

\subsection{Factors Associated with $H B V$ Infection}

3.5.1. History of Multiple Sexual Partners. Sixteen studies, 5111 pregnant women, were included in this category of 


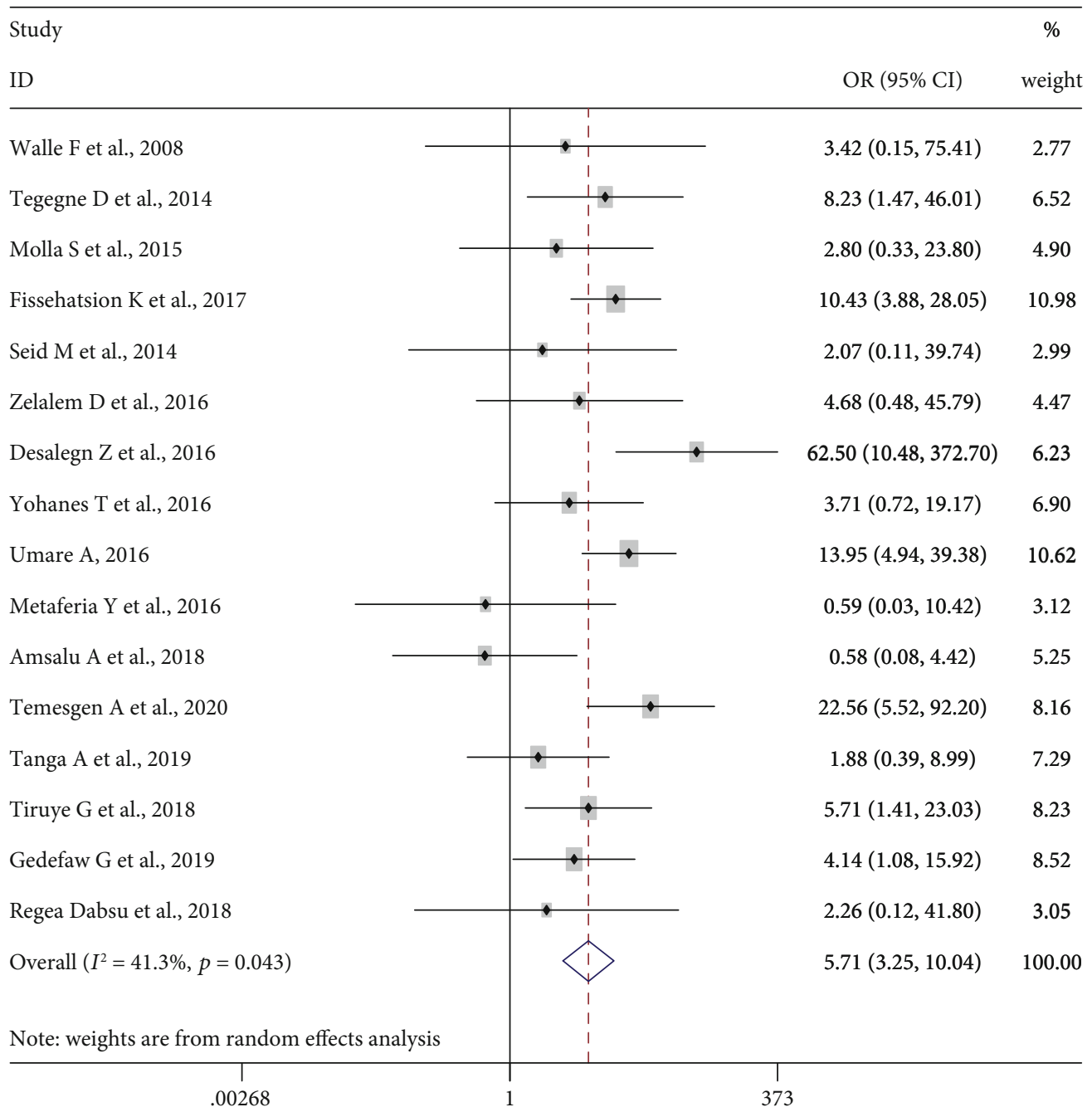

FIgURE 4: Forest plot on the effect of history of blood transfusion on HBV infection.

meta-analysis. Ten of the included studies $[11,23,29,30,42-$ 47] showed the presence of association of multiple sexual partners with a higher risk of $\mathrm{HBV}$ infection. The metaanalysis showed a strong association between the history of multiple sexual partners and $\mathrm{HBV}$ infection, $\mathrm{OR}=6.02$ (95\% CI: 3.86, 9.36). The heterogeneity test showed statistical evidence of heterogeneity, $I^{2}=48 \%$ and $p$ value $=0.017$. Begg's and Egger's tests for publication bias also showed no statistical evidence of publication bias, $p$ value $=0.368$ and $p$ value $=0.370$, respectively (Figure 3 ).

3.5.2. History of Blood Transfusion. Sixteen studies, 4910 pregnant women, were included in this category of metaanalysis $[11,23,24,29-35,41-45]$. Seven of the included studies [11, 32, 34, 41-44] showed a significant association between history of blood transfusion and a higher risk of HBV infection. The pooled meta-analysis showed higher odds of HBV infection among pregnant women who had a history of blood transfusion than those who had no history of blood transfusion, $\mathrm{OR}=5.71(95 \% \mathrm{CI}=3.25,10.04)$.
Significant heterogeneity $\left(I^{2}=41.3 \%, p\right.$ value $\left.=0.043\right)$ was found, whereas Begg's tests showed no statistical evidence of publication bias, $p$ value $=0.150$ (Figure 4 ).

3.5.3. History of Abortion. Fifteen studies [11, 23, 29-31, 33$37,41,44,45,47], 4,854$ pregnant women, were included to determine the association of history of abortion and HBV infection. The pooled meta-analysis showed that pregnant women who had an abortion are more than three or more times more likely to be infected with $\mathrm{HBV}, \mathrm{OR}=3.58$ (95\% CI: 2.10, 6.09). Heterogeneity test showed evidence of high heterogeneity, $I^{2}=65.3 \%$ and $p$ value $\leq 0.001$. However, there was nonsignificant publication bias, Begg's test $=$ 0.961 and Egger's test $=0.855$ (Figure 5).

3.6. Body Tattoo. Fourteen studies [24, 29, 31-37, 41, 44-46], 4336 pregnant women, were included to determine the association of history of abortion and HBV infection. The pooled meta-analysis showed that pregnant women who had an abortion are more than three or more times more likely to 


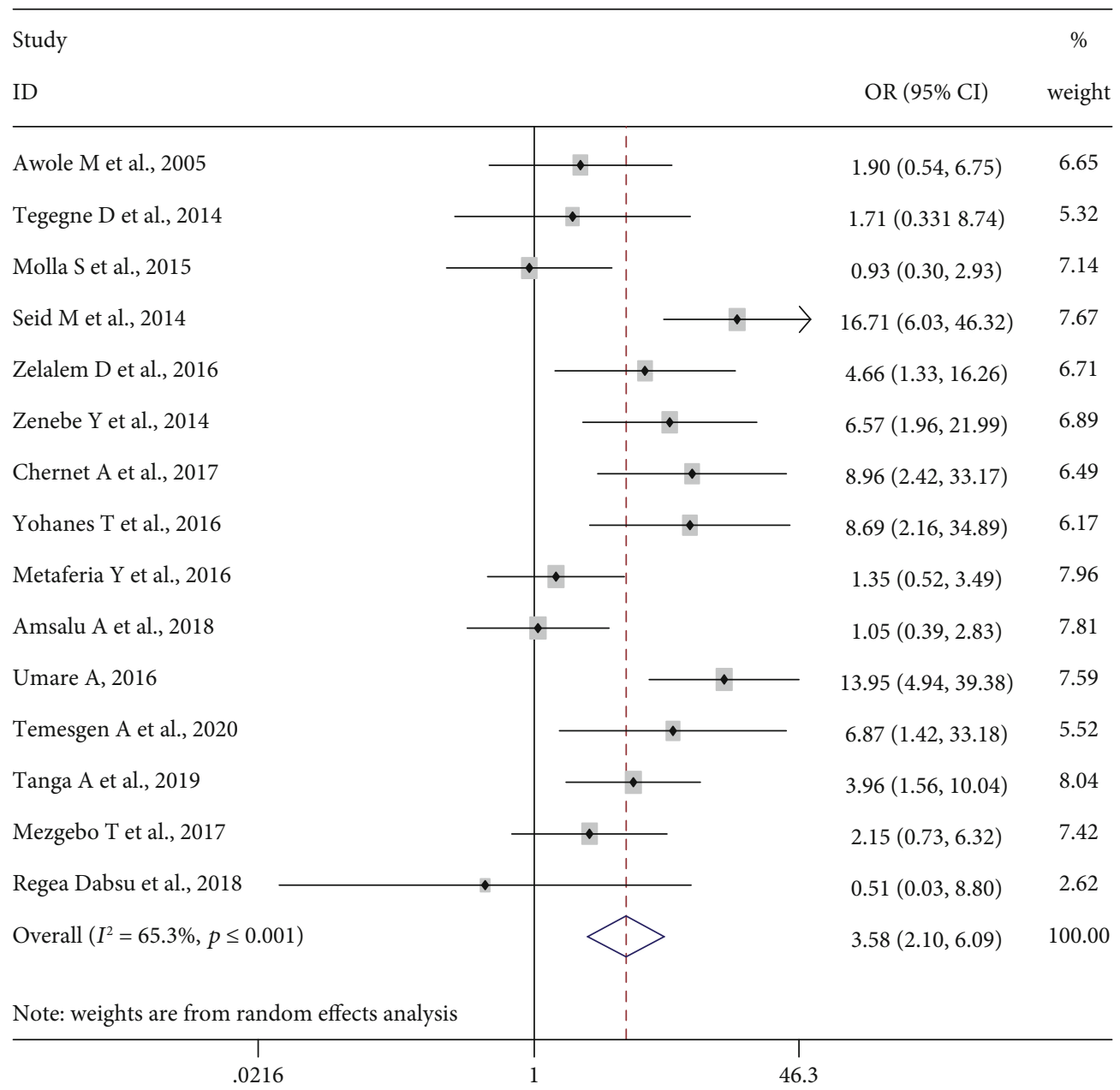

FIgURE 5: Forest plot on the effect of history of abortion on HBV infection.

be infected with $\mathrm{HBV}, \mathrm{OR}=2.83$ (95\% CI: 1.55, 5.17). Heterogeneity test showed evidence of high heterogeneity, $I^{2}$ $=69.4 \%$ and $p$ value $\leq 0.001$. However, there was nonsignificant publication bias, Begg's test $=0.956$ and Egger's test $=0.838$ (Figure 6).

\section{Discussion}

HBV infection screening and treatment among pregnant women in addition to universal newborn vaccination [48, 49] are important to prevent perinatal mortality [38] whereas screening pregnant women for hepatitis B infection based on risk factors may not be effective [50]. Vaccination of neonates of $\mathrm{HBV}$-positive mothers within 24 hours of delivery prevents $90-95 \%$ of transmission [2]. Moreover, health education on routes of transmission has paramount importance on $\mathrm{HBV}$ infection prevention $[29,51]$.

We have investigated the prevalence and associated factors of HBV infection among pregnant women in Ethiopia, considering it will be an input for the government, nongovernmental organizations, and stakeholders who want to work on limiting and reducing it. This systematic review and metaanalysis found that the pooled national level prevalence of HBV infection among pregnant women was $4.75 \%(95 \%$
CI: 4.06, 5.44), ranged as intermediate according to the WHO classification [52]. It was almost similar to a metaanalysis study in Ethiopia (4.7\%) [13]. This similarity might be due to the fact that both studies are nationwide and have similar study population. However, the prevalence of this study was lower than that of a nationwide study done in other developing countries such as in Ghana (12.3\%) [3], Cameroon (11.2\%) [53], and Nigeria (13.6\%) [54]. It might be attributed to the high prevalence of $\mathrm{HBV}$ infection among the general population of the countries [13] which is higher than the prevalence of HBV infection of the general population in Ethiopia 7.4\% [22]. Generally, its heavy burden of high cost for prevention, treatment, and management [55] makes HBV infection higher in developing countries than in developed countries. This is supported by the studies that showed less prevalence of HBV infection among pregnant women in developed countries, i.e., Denmark (0.26\%) [49], Turkey (1.74\%) [56], and Spain (0.1\%) [57]. This lower prevalence might be due to universal screening and vaccination; universal screening for hepatitis $\mathrm{B}$ has increased vaccination coverage up to $96 \%$ among pregnant women [49].

Furthermore, this systematic review and meta-analysis found that pregnant women who had a history of blood 


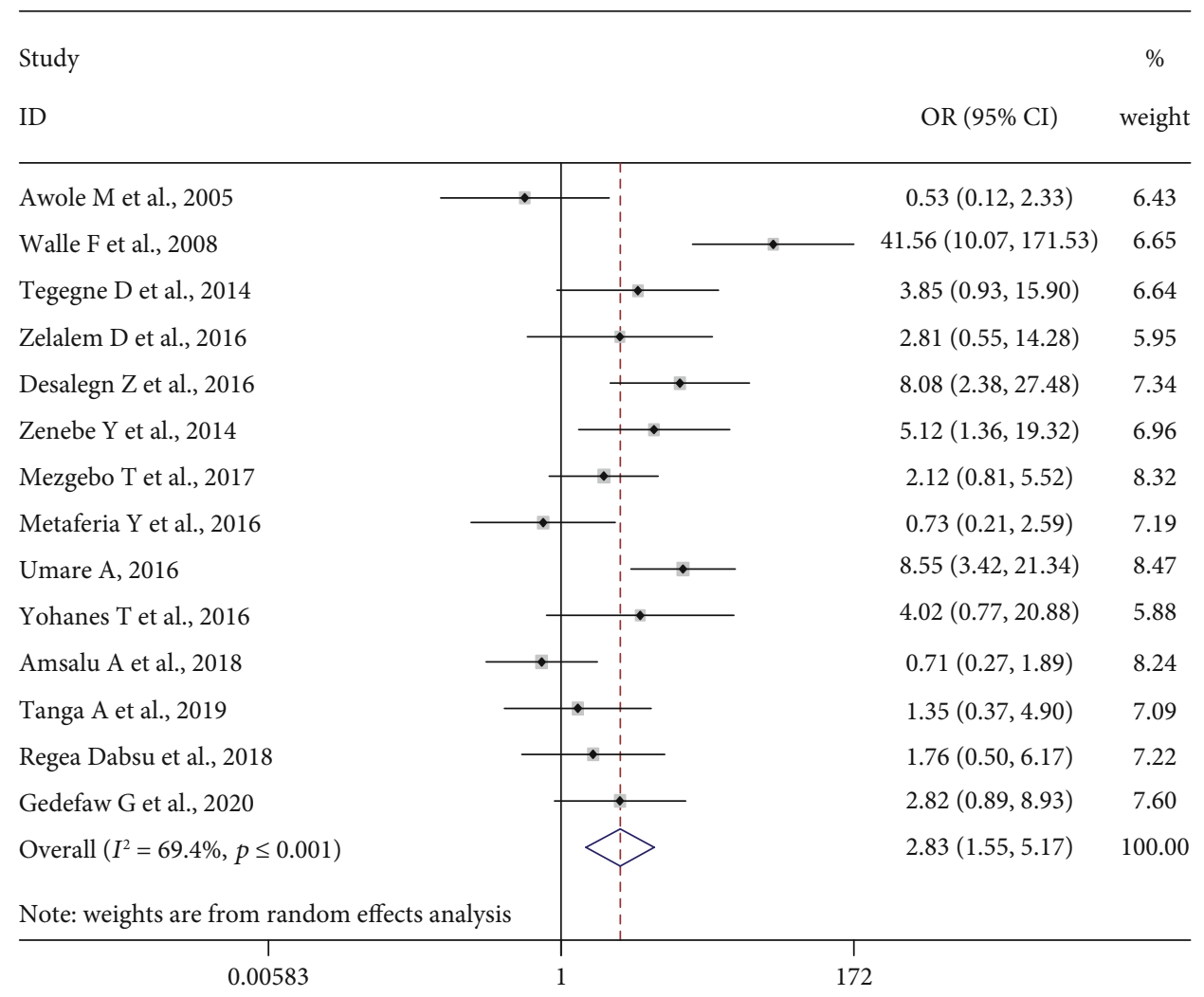

FIGURE 6: Forest plot on the effect of body tattooing on HBV infection.

transfusion were more likely to be infected with HBV, which is supported by the studies done in Ethiopia [36], Pakistan [58], Nigeria [59], Congo [58], Cameroon [60], Uganda [61], and Sudan [62]. This might be attributed to the incomplete screening coverage before donation [63].

This study also identified pregnant women who had multiple sexual partners significantly associated with $\mathrm{HBV}$ infection in Ethiopia. This is similar to studies done in Ethiopia [44], Nigeria [59], India [64], and South Sudan [65]. It might be due to $\mathrm{HBV}$ transmitted through sexual intercourse, and when it is unprotected and is done with multiple partners, the transmission rate will be increased. Similarly, this study showed pregnant women who had abortion history are more likely to be infected with HBV which is also in line with other previous studies done in Ethiopia [11], Kenya [66], Nigeria [67], Sudan [68], and Uganda [61] in which it might be attributed by the fact that most of the common causes of abortion is unplanned pregnancy and with unprotected sexual intercourse that makes them prone to communicable disease.

Moreover, this systematic review and meta-analysis also revealed that pregnant women who had a tattoo on their body were infected with HBV more likely than those who had not, similarly with the studies done in Ethiopia [36, 41], Sudan [68], Turkey [51], Ghana [51], Nigeria [59], and Rwanda [69]. It might be due to a gap in the cleaning and sterilizing of materials for the procedure. The outcome variable may be affected by other variables not included in this study.

\section{Conclusions}

The prevalence of HBV infection among pregnant women in Ethiopia is intermediate though variations are observed across regions. A higher risk of $\mathrm{HBV}$ infection was observed among pregnant women who had a history of abortion, who had a blood transfusion, who had a tattoo on their body, and who had multiple sexual partners. This study identified the magnitude and some of the factors associated with $\mathrm{HBV}$ infection. Therefore, the Ministry of Health and other concerned organizations should take note of this evidence to prevent further infection of $\mathrm{HBV}$.

\section{Abbreviations}

HBV: Hepatitis B virus

CI: $\quad$ Confidence interval

OR: $\quad$ Odds ratio

SNNPR: Southern Nations, Nationalities, and Peoples' Region

WHO: World Health Organization

PRISMA: The Preferred Reporting Items for Systematic Reviews and Meta-Analysis

SE: $\quad$ Standard error.

\section{Data Availability}

Data used in the current study are available from authors of each study upon request. 


\section{Conflicts of Interest}

We declare no competing interests.

\section{Authors' Contributions}

AAA involved in the design, selection of articles, data extraction, statistical analysis, and manuscript writing of this review whereas LBZ, BYA, and GMK involved in data extraction, statistical analysis, and reviewing and editing the manuscript. All authors approved the final manuscript.

\section{Acknowledgments}

All authors of the studies included in this systematic and meta-analysis are gratefully acknowledged.

\section{Supplementary Materials}

PRISMA NMA checklist of items to include when reporting a systematic review involving a network meta-analysis. (Supplementary Materials)

\section{References}

[1] M. Blachier, H. Leleu, M. Peck-Radosavljevic, D.-C. Valla, and F. Roudot-Thoraval, "The burden of liver disease in Europe: a review of available epidemiological data," Journal of Hepatology, vol. 58, no. 3, pp. 593-608, 2013.

[2] World Health Organization, Guidelines on hepatitis B and C testing, Who, 2017, https://apps.who.int/iris/bitstream/han dle/10665/254621/9789241549981-eng.pdf?sequence=1\%0A http://apps.who.int/iris/bitstream/10665/254621/1/978924154 9981-eng.pdf?ua=1\%0Ahttp://www.ncbi.nlm.nih.gov/pub med/28742301\%0Ahttp://www.ncbi.nlm.nih.gov/pubmed/ 2874.

[3] R. Ofori-Asenso and A. A. Agyeman, "Hepatitis B in Ghana: a systematic review \& meta-analysis of prevalence studies (19952015)," BMC Infectious Diseases, vol. 16, no. 1, 2016.

[4] D. Gebreegziabher, G. G. Asfeha, and H. A. Gebreyesus, "Seroprevalence of hepatitis B virus surface antigen (HBsAg) among clients visiting "Tefera Hailu" memorial hospital, Sekota, Northern Ethiopia," BMC Infectious Diseases, vol. 16, no. 1, pp. 1-6, 2016.

[5] W. E. Crusio, J. D. Lambris, and N. Rezaei, Hepatitis B Virus Infection Molecular Virology to Antiviral Drugs, vol. 1179 of Advances in Experimental Medicine and Biology.

[6] H. Afzali, M. Momen Heravi, S. A. Moravveji, and M. Poorrahnama, "Prevalence of hepatitis B surface antigen in pregnant women in Beheshti Hospital of Kashan, Isfahan," Iranian Red Crescent Medical Journal, vol. 17, no. 7, pp. e20598-e20596, 2015.

[7] S. Pungpapong, W. R. Kim, and J. J. Poterucha, "Natural history of hepatitis B virus infection: an update for clinicians," Mayo Clinic Proceedings, vol. 82, no. 8, pp. 967-975, 2007.

[8] M. Lemoine, S. Eholié, and K. Lacombe, "Reducing the neglected burden of viral hepatitis in Africa: strategies for a global approach," Journal of Hepatology, vol. 62, no. 2, pp. 469-476, 2015.

[9] A. S. Lok, "Chronic hepatitis B," The New England Journal of Medicine, vol. 346, no. 22, pp. 1682-1683, 2002.
[10] V. C. W. Wong, H. W. Reesink, H. M. H. Ip et al., "Prevention of the hbsag carrier state in newborn infants of mothers who are chronic carriers of hbsag and hbeag by administration of hepatitis-b vaccine and hepatitis-b immunoglobulin: doubleblind randomised placebo-controlled study," The Lancet, vol. 323, no. 8383, pp. 921-926, 1984.

[11] T. A. Bafa and A. D. Egata, "Seroepidemiological patterns and predictors of hepatitis B, C and HIV viruses among pregnant women attending antenatal care clinic of Atat Hospital, Southern Ethiopia," SAGE Open Medicine, vol. 8, 2020.

[12] A. Negero, Z. Sisay, and G. Medhin, "Prevalence of hepatitis B surface antigen (HBsAg) among visitors of Shashemene General Hospital voluntary counseling and testing center," BMC Research Notes, vol. 4, no. 1, p. 35, 2011, http://www. biomedcentral.com/1756-0500/4/35.

[13] K. M. Kebede, D. D. Abateneh, and A. S. Belay, "Hepatitis B virus infection among pregnant women in Ethiopia : a systematic review and meta-analysis of prevalence studies," pp. 1-9, 2018.

[14] C. Deme, B. Edao, G. Jaya et al., "Prevalence of hypertension, anemia, asymptomatic urinary tract infection, syphilis, HIV and hepatitis B virus infection among pregnant women attending an antenatal clinic at a rural hospital in southern Ethiopia," The Southeast Asian journal of tropical medicine and public health, vol. 47, no. 5, pp. 1032-1039, 2016, http:// europepmc.org/abstract/MED/29620811.

[15] N. C. Vu Lam, P. B. Gotsch, and R. C. Langan, "Caring for pregnant women and newborns with hepatitis B or C," American Family Physician, vol. 82, no. 10, pp. 1225-1229, 2010.

[16] C. L. Lai, V. Ratziu, M. F. Yuen, and T. Poynard, "Viral hepatitis B," The Lancet, vol. 362, no. 9401, pp. 2089-2094, 2003.

[17] R. Vranckx, A. Alisjahbana, and A. Meheus, "Hepatitis B virus vaccination and antenatal transmission of $\mathrm{HBV}$ markers to neonates," Journal of Viral Hepatitis, vol. 6, no. 2, pp. 135139, 2002.

[18] Y. M. Song, J. Sung, S. Yang, Y. H. Choe, Y. S. Chang, and W. S. Park, "Factors associated with immunoprophylaxis failure against vertical transmission of hepatitis B virus," European Journal of Pediatrics, vol. 166, no. 8, pp. 813-818, 2007.

[19] A. Hillary, M. Sezalio, B. Pauline et al., "Prevalence and factors associated with hepatitis B surface antigen positivity among women receiving antenatal care at Mbarara Regional Referral Hospital," Journal of Tropical Diseases \& Public Health, vol. 7, no. 5, pp. 1-10, 2019.

[20] M. Geta, G. Ayalew, E. Yizengaw, A. Mihret, A. Aseffa, and R. Howe, Original article seroprevalence of hepatitis $B$ virus infection and associated factors among mothers in Gondar, North-west Ethiopia, 2019.

[21] P. Bayo, E. Ochola, C. Oleo, and A. D. Mwaka, "High prevalence of hepatitis B virus infection among pregnant women attending antenatal care: a cross-sectional study in two hospitals in northern Uganda," BMJ Open, vol. 4, no. 11, pp. e005889-e005887, 2014.

[22] E. Keane, A. L. Funk, and Y. Shimakawa, "Systematic review with meta-analysis: the risk of mother-to-child transmission of hepatitis B virus infection in sub-Saharan Africa," Alimentary Pharmacology \& Therapeutics, vol. 44, no. 10, pp. 10051017, 2016.

[23] M. Seid, B. Gelaw, and A. Assefa, "Sero-prevalence of HBV and HCV infections among pregnant women attending antenatal care clinic at Dessie Referral Hospital, Ethiopia," 
Advances in Life Sciences and Health, vol. 1, no. 2, pp. 109120, 2014.

[24] D. Moher, L. Shamseer, M. Clarke et al., "Preferred reporting items for systematic review and meta-analysis protocols (PRISMA-P) 2015 statement," Systematic Reviews, vol. 4, no. $1,2015$.

[25] P. A. Modesti, G. Reboldi, F. P. Cappuccio et al., "Panethnic differences in blood pressure in Europe: a systematic review and meta-analysis," PLoS One, vol. 11, no. 1, article e0147601, 2016.

[26] J. P. T. Higgins, S. G. Thompson, J. J. Deeks, and D. G. Altman, "Measuring inconsistency in meta-analyses," BMJ, vol. 327, no. 7414, pp. 557-560, 2003.

[27] M. Egger, G. D. Smith, M. Schneider, and C. Minder, "Bias in meta-analysis detected by a simple, graphical test," BMJ, vol. 315, no. 7109, pp. 629-634, 1997.

[28] C. B. Begg and M. Mazumdar, "Operating characteristics of a rank correlation test for publication bias," Biometrics, vol. 50, no. 4, pp. 1088-1101, 1994.

[29] A. Amsalu, G. Ferede, S. Eshetie, A. Tadewos, and D. Assegu, "Prevalence, infectivity, and associated risk factors of hepatitis $B$ virus among pregnant women in Yirgalem Hospital, Ethiopia: implication of screening to control mother-to-child transmission," Journal of Pregnancy, vol. 2018, 8 pages, 2018.

[30] S. Molla, A. Munshea, and E. Nibret, "Seroprevalence of hepatitis B surface antigen and anti HCV antibody and its associated risk factors among pregnant women attending maternity ward of Felege Hiwot Referral Hospital, northwest Ethiopia: a cross-sectional study," Virology Journal, vol. 12, no. 1, 2015.

[31] F. Walle, D. Asrat, A. Alem, E. Tadesse, and K. Desta, "Prevalence of hepatitis b surface antigen among pregnant women attending antenatal care service at Debre-Tabor Hospital, northwest Ethiopia," Ethiopian Journal of Health Sciences, vol. 17, no. 17, pp. 13-20, 2008.

[32] G. Gedefaw, F. Waltengus, A. Akililu, and K. Gelaye, "Risk factors associated with hepatitis B virus infection among pregnant women attending antenatal clinic at Felegehiwot referral hospital, Northwest Ethiopia, 2018: an institution based cross sectional study," BMC Research Notes, vol. 12, article 509, 2019.

[33] R. Dabsu and E. Ejeta, "Seroepidemiology of hepatitis B and C virus infections among pregnant women attending antenatal clinic in selected health facilities in East Wollega Zone, West Oromia, Ethiopia," BioMed Research International, vol. 2018, 9 pages, 2018.

[34] D. Tegegne, K. Desta, B. Tegbaru, and T. Tilahun, "Seroprevalence and transmission of hepatitis B virus among delivering women and their new born in selected health facilities, Addis Ababa, Ethiopia: a cross sectional study," BMC Research Notes, vol. 7, no. 1, pp. 1-7, 2014.

[35] Y. Metaferia, W. Dessie, I. Ali, and A. Amsalu, "Seroprevalence and associated risk factors of hepatitis B virus among pregnant women in southern Ethiopia: a hospital-based cross-sectional study," Epidemiology and Health, vol. 38, article e2016027, 2016.

[36] Y. Zenebe, W. Mulu, M. Yimer, and B. Abera, "Sero-prevalence and risk factors of hepatitis $\mathrm{C}$ virus infection among pregnant women in Bahir Dar city, Northwest Ethiopia: cross sectional study," The Pan African Medical Journal, vol. 21, pp. 1-7, 2015.
[37] M. Awole and S. Gebre-Selassie, "Seroprevalence of HBsAg and its risk factors amoung pregnant women in Jimma, Southwest Ethiopia," Ethiopian Journal of Health Development, vol. 19, no. 1, 2005.

[38] A. Schönfeld, T. Feldt, T. B. Tufa et al., "Prevalence and impact of sexually transmitted infections in pregnant women in central Ethiopia," International Journal of STD \& AIDS, vol. 29, no. 3, pp. 251-258, 2017.

[39] J. M. Ramos, C. Toro, F. Reyes, A. Amor, and F. Gutiérrez, "Seroprevalence of HIV-1, HBV, HTLV-1 and Treponema pallidum among pregnant women in a rural hospital in Southern Ethiopia," Journal of Clinical Virology, vol. 51, no. 1, pp. 83-85, 2011.

[40] Z. Desalegn, A. Mihret, H. B. Beyene et al., "Survey of hepatitis $B$ virus infection and risk factors among pregnant women at a public hospital in Ethiopia," International Journal of Biomedical Research, vol. 7, no. 7, pp. 450-456, 2016.

[41] Z. Desalegn, L. Wassie, H. B. Beyene, A. Mihret, and Y. A. Ebstie, "Hepatitis B and human immunodeficiency virus coinfection among pregnant women in resource-limited high endemic setting, Addis Ababa, Ethiopia: implications for prevention and control measures," European Journal of Medical Research, vol. 21, no. 1, pp. 1-7, 2016.

[42] K. Fissehatsion, I. Ali, and A. Getachew, "Seroprevalence and risk factors of sexually transmitted infections (HIV, HBV and syphilis) among pregnant women provided health care services, Addis Ababa, Ethiopia," American Journal of Health Research, vol. 5, no. 5, pp. 154-161, 2017, http://www.science publishinggroup.com/j/ajhr.

[43] G. Tiruye, K. Shiferaw, and F. Tadesse, "Seroprevalence of hepatitis B virus infection and associated factors among pregnant women attended antenatal care services in Harar City, Eastern Ethiopia," Journal of Women's Health Care, vol. 7, no. 3, pp. 310, 2018.

[44] A. Umare, B. Seyoum, T. Gobena, and T. H. Mariyam, "Hepatitis B virus infections and associated factors among pregnant women attending antenatal care clinic at Deder Hospital, Eastern Ethiopia," PLoS One, vol. 11, no. 11, article e0166936, 2016.

[45] A. T. Tanga, M. A. Teshome, D. Hiko, C. Fikru, and G. K. Jilo, "Sero-prevalence of hepatitis B virus and associated factors among pregnant women in Gambella hospital, South Western Ethiopia: facility based cross-sectional study," BMC Infectious Diseases, vol. 19, no. 1, pp. 602-607, 2019.

[46] T. A. Mezgebo, S. Niguse, A. G. Kahsay, H. Hailekiros, N. Berhe, and T. A. Dejene, "Hepatitis B virus infection and associated risk factors among pregnant women attending antenatal care in health facilities of Tigray, Northern Ethiopia," Journal of Medical Virology, vol. 90, no. 3, pp. 503-509, 2018.

[47] A. Chernet, A. Yesuf, and A. Alagaw, "Seroprevalence of hepatitis B virus surface antigen and factors associated among pregnant women in Dawuro zone, SNNPR, Southwest Ethiopia: a cross sectional study," BMC Research Notes, vol. 10, no. 1, pp. 418-415, 2017.

[48] M. Al-Essa, A. Alyahya, A. Al Mulhim, A. Alyousof, M. Almulhim, and A. Essa, "Perception of and attitude towards hepatitis B infection among Saudi pregnant females attending antenatal care unit in Al-Ahsa City, Kingdom of Saudi Arabia," Cureus, vol. 12, no. 1, pp. 1-11, 2020.

[49] K. M. Harder, S. Cowan, M. B. Eriksen, H. B. Krarup, and P. B. Christensen, "Universal screening for hepatitis B among pregnant women led to $96 \%$ vaccination coverage 
among newborns of HBsAg positive mothers in Denmark," Vaccine, vol. 29, no. 50, pp. 9303-9307, 2011.

[50] K. A. Rabiu, O. I. Akinola, A. A. Adewunmi, O. M. Omololu, and T. O. Ojo, "Risk factors for hepatitis B virus infection among pregnant women in Lagos, Nigeria," Acta Obstetricia et Gynecologica Scandinavica, vol. 89, no. 8, pp. 1024-8, 2010.

[51] S. Cetin, M. Cetin, E. Turhan, and K. Dolapcioglu, "Seroprevalence of hepatitis B surface antigen and associated risk factors among pregnant women," Journal of Infection in Developing Countries, vol. 12, no. 10, pp. 904-909, 2018.

[52] T. Powell, "A mathematical model for calcium homeostasis," The Bulletin of Mathematical Biophysics, vol. 34, no. 4, pp. 483-502, 1972.

[53] J. J. Bigna, M. A. Amougou, S. L. Asangbeh et al., "Seroprevalence of hepatitis B virus infection in Cameroon: a systematic review and meta-analysis," BMJ Open, vol. 7, no. 6, article e015298, 2017.

[54] B. M. Musa, A. A. Samaila, O. L. Femi, M. M. Borodo, and S. Bussell, "Prevalence of hepatitis B virus infection in Nigeria, 2000-2013 : a systematic review and meta-analysis," Nigerian Journal of Clinical Practice, vol. 18, no. 2, pp. 163-172, 2015.

[55] R. Zampino, A. Boemio, C. Sagnelli et al., "Hepatitis B virus burden in developing countries," World Journal of Gastroenterology, vol. 21, no. 42, pp. 11941-11953, 2015.

[56] Y. Ali, A. Akif, and A. Sibel, "An unexpected low hepatitis B seroprevalence in pregnant women from the rural southeastern Turkey," African Journal of Microbiology Research, vol. 5, no. 23, pp. 3942-3945, 2011.

[57] L. Salleras, A. Domínguez, M. Bruguera et al., "Seroepidemiology of hepatitis B virus infection in pregnant women in Catalonia (Spain)," Journal of Clinical Virology, vol. 44, no. 4, pp. 329-332, 2009.

[58] M. Ali, M. Idrees, L. Ali et al., "Hepatitis B virus in Pakistan: a systematic review of prevalence, risk factors, awareness status and genotypes," Virology Journal, vol. 8, no. 1, pp. 102-109, 2011.

[59] C. G. Anaedobe, A. Fowotade, C. Omoruyi, and R. Bakare, "Prevalence, socio-demographic features and risk factors of hepatitis B virus infection among pregnant women in Southwestern Nigeria," The Pan African Medical Journal, vol. 20, pp. 1-11, 2015.

[60] J. J. N. Noubiap, J. R. N. Nansseu, S. T. Ndoula, J. J. R. Bigna, A. M. Jingi, and J. Fokom-Domgue, "Prevalence, infectivity and correlates of hepatitis B virus infection among pregnant women in a rural district of the Far North Region of Cameroon," BMC Public Health, vol. 15, no. 1, pp. 1-7, 2015.

[61] S. P. Kayondo, Prevalence and factors associated with hepatitis $B$ virus infection among pregnant women attending antenatal care clinic in Mulago Hospital, David Publishing, 2019.

[62] M. H. Abuelgasim and M. B. K. Baraka, "Prevalence of hepatitis B infection among pregnant women at Khartoum Teaching Hospital, Sudan," Journal of US-China Medical Science, vol. 12, no. 2, pp. 58-63, 2015.

[63] S. Jayaraman, Z. Chalabi, P. Perel, C. Guerriero, and I. Roberts, "The risk of transfusion-transmitted infections in sub-Saharan Africa," Transfusion, vol. 50, no. 2, pp. 433-442, 2010.

[64] N. Samal, S. Padhi, and L. Burman, "Seroprevalence of hepatitis B infection among pregnant women in Southern Odisha," Indian Journal of Medical Specialities, vol. 10, no. 4, p. 207, 2019.
[65] A. L. S. Kirbak, Z. Ng'ang'a, J. Omolo, H. Idris, A. Usman, and W. B. Mbabazi, "Sero-prevalence for hepatitis b virus among pregnant women attending antenatal clinic in Juba Teaching Hospital, Republic of South Sudan," The Pan African Medical Journal, vol. 26, pp. 1-7, 2017.

[66] J. A. M. Ngaira, J. Kimotho, I. Mirigi et al., "Prevalence, awareness and risk factors associated with hepatitis b infection among pregnant women attending the antenatal clinic at Mbagathi District Hospital in Nairobi, Kenya," Pan African Medical Journal, vol. 24, pp. 1-7, 2016.

[67] C. A. Omatola, C. Lawal, D. O. Omosayin et al., "Seroprevalence of HBV, HCV, and HIV and associated Risk factors among apparently healthy pregnant women in Anyigba, Nigeria," Viral Immunology, vol. 32, no. 4, pp. 186-191, 2019.

[68] R. A. El Gasim, N. Eltayeb, and I. El Khidir, "Hepatitis B virus infection in pregnant women, in Al Fashir Town, North Darfur State, Sudan," Open Journal of Medical Microbiology, vol. 9, no. 1, pp. 28-36, 2019.

[69] J. D. Makuza, J. O. T. Rwema, C. K. Ntihabose et al., "Prevalence of hepatitis B surface antigen ( $\mathrm{HBsAg}$ ) positivity and its associated factors in Rwanda," BMC Infectious Diseases, vol. 19, no. 1, pp. 381-310, 2019. 